\title{
Expression Profiling of Breast Tumors Based on Human Epidermal Growth Factor Receptor 2 Status Defines Migration-Related Genes
}

\author{
M. Cuadros ${ }^{a, c}$ C. Cano ${ }^{c}$ F.J. López ${ }^{c} \quad$ R. López-Castro ${ }^{a} \quad$ A. Concha ${ }^{a, b}$ \\ ${ }^{a}$ Department of Pathology, ${ }^{\mathrm{b}}$ Tissue and Tumor Bank, Department of Pathology, Hospital Universitario Virgen de las \\ Nieves, and ${ }^{\mathrm{C}}$ Department of Computer Science and Artificial Intelligence, University of Granada, Granada, Spain
}

\section{Key Words}

Breast neoplasm · Gene expression profile $\cdot$ Human

epidermal growth factor receptor $2 /$ neu

\begin{abstract}
Objective: Breast cancer is a heterogeneous neoplasm. Distinct subtypes of breast cancer have been defined, suggesting the existence of molecular differences contributing to their clinical outcomes. However, the molecular differences between human epidermal growth factor receptor 2 (HER2)positive and HER2-negative breast cancer tumors remain unclear. The aim of this study was to identify a gene expression profile for breast tumors based on their HER2 status. Methods: The HER2 status was determined by immunohistochemistry (IHC) and fluorescence in situ hybridization (FISH) in 54 breast tumor samples. Using Affymetrix microarray data from these breast tumors, we established the expression profiling of breast cancer based on HER2 IHC and FISH results. To validate microarray experiment data, real-time quantitative reverse transcription-PCR was performed. $\boldsymbol{R} \boldsymbol{e}-$ sults: We found significant differences between the HER2positive and HER2-negative breast tumor samples, which included overexpression of HER2, other genes located on $17 q 12$ and genes functionally related to migration. Conclu-
\end{abstract}

sion: Our study shows the potential of integrated genomic profiling to shed light on the molecular knowledge of HER2positive breast tumors.

Copyright $\odot 2012$ S. Karger AG, Basel

\section{Introduction}

The human epidermal growth factor receptor 2 (HER2) oncogene plays an important role in the development and progression of breast cancer, and is amplified in approximately $25-30 \%$ of human breast tumors $[1,2]$. The response to targeted anti-HER2 therapy (trastuzumab) depends on HER2 overexpression [3], but resistance to trastuzumab is frequent [4]. To assess a patient's eligibility to receive trastuzumab, HER2 status is determined in routine practice by 2 diagnostic techniques, immunohistochemistry (IHC) and fluorescent in situ hybridization (FISH), which are often used together on processed paraffin-embedded block tissue sections. FISH, particularly, is considered a superior method for selecting patients likely to benefit from a trastuzumab treatment.

M.C. and C.C. contributed equally to this work.

\section{KARGER}

Fax +4161306 1234

E-Mail karger@karger.ch

www.karger.com
(C) 2012 S. Karger AG, Basel

$1015-2008 / 13 / 0801-0032 \$ 38.00 / 0$

Accessible online at:

www.karger.com/pat
Marta Cuadros, $\mathrm{PhD}$

Department of Computer Science and Artificial Intelligence University of Granada

c/. Daniel Saucedo Aranda, s/n, ES-18071 Granada (Spain)

Tel. +34 958241 773, E-Mail marta@ decsai.ugr.es 
However, the response rate in tumors which overexpress and amplify HER2 according to these techniques is modest [5].

High throughput gene expression profiling with microarrays enables the analysis of the expression of thousands of genes in a single experiment, providing complex and detailed data. Gene expression profiling of breast tumors has been shown to be effective in identifying different tumor subtypes (luminal A and B, HER2, basal-like and normal breast-like) which are related to distinct clinical outcomes [6-10]. In addition, different gene signatures obtained from the analysis of cDNA microarray data, such as the 70-gene MammaPrint signature [11] and the 76-signature [12], might provide prognostic information, as well as help to individualize treatments in the increasing breast cancer population $[13,14]$. However, few studies have focused on the comparison of expression profiles between patients with different HER2 status according to IHC and FISH scores [15-18]. This is surprising, since breast cancer patients are classified in the clinic on the basis of HER2 status, and the role of HER 2 in the oncogenesis remains unclear [19].

In this work, a gene expression microarray analysis of 54 breast cancer tumors was performed. They were classified into 4 groups according to their HER2 status determined by IHC and FISH. The goal of the study was to establish the gene expression profiling of breast cancers based on their HER2 status. This knowledge could help in the understanding of their behavior and to design new therapeutic strategies. The results show a large number of genes which exhibit a significant differential expression between HER2 FISH-positive and HER2 FISH-negative tumors. Furthermore, we show that the genes that better differentiate these subgroups include genes located on 17q12 and genes involved in the migration process.

\section{Methods}

The patients participating in this study provided written acknowledgement and informed consent in accordance with institutional and national guidelines.

\section{Patient Identification}

The tumor samples under study correspond to 54 primary breast carcinomas. They included cases with an HER2 IHC3+ score with HER2 gene amplification, cases with an IHC2+ score with and without HER2 gene amplification and cases IHC0/1+ score without HER2 gene amplification. To compare the gene expression pattern of the tumors, we also used 12 samples of breast normal tissues from breast cancer patients. Neither overexpres-

Expression Profiling of Breast Tumors

Based on HER2 Status sion nor amplification of HER2 was observed. Frozen sample materials were provided by the Tissue and Tumor Bank, Department of Pathology, Hospital Universitario Virgen de las Nieves. Demographic data, tumor stage, histology at presentation, IHC markers [such as hormone receptor estrogen and progesterone, p53, ki67 and HER2], HER2 DNA amplification and polysomy 17 were also recorded by the Department of Pathology at the hospital (see table 1).

\section{RNA Isolation}

RNAs were extracted from macrodissected frozen samples according to standard procedures using Trizol reagent (Invitrogen, Carlsbad, Calif., USA). Quantity and integrity of RNAs were checked by spectrophotometry and the Agilent 2100 Bioanalyzer, respectively. The amount of tumoral cells was evaluated by microscopic evaluation of hematoxylin- and eosin-stained sections. Only samples of tumors with $\geq 60 \%$ tumoral cells were included in this study.

\section{Inmunohistochemical Markers}

The expression of p53 and ki67 was assessed according to the estimated proportion of nuclear staining in tumor cells that were positively stained. The estrogen receptor and progesterone receptor expression was quantified by using the Allred scoring, which is a microscopic method conveying the estimated percentage of cells that stained and the intensity of their staining (range $0-8$ ). Values of the Allred index over 3 are considered positive [20].

\section{HER2 Detection by Immunohistochemistry}

Paraffin-embedded tissue sections were stained by the same technician with Hercep Test ${ }^{\mathrm{TM}}$ (Dako Diagnostic) in an automatic stainer (Autostainer plus ${ }^{\mathrm{TM}}$, Dako Diagnostic) and the degree of staining was scored by a blinded pathologist (A.C.) according to the Hercep Test criteria and the HER2 testing guidelines of the American Society of Clinical Oncology and the College of American Pathologists [21-23].

\section{HER2 FISH Analysis}

FISH was performed on all paraffin-embedded tissue and cut into 4 - to 5 - $\mu \mathrm{m}$ sections using HER2 FISH pharmDx ${ }^{\mathrm{TM}}$ (Dako Diagnostic). FISH was carried out according to the method recommended by Dako. FISH testing results are a semiquantitative method based on the average ratio of Her2/neu signals to CEP17 signals in the nonoverlapping interphase nuclei of the lesion. Specimens with an HER2: CEP17 ratio of $\geq 2: 2$ were considered positive for gene amplification. The HER2: CEP17 signals were visualized by a blinded pathologist (A.C.). This test allowed a simultaneous determination of chromosome 17 copies. The polysomy 17 was defined as the occurrence of 3 or more copy numbers of centromeres for chromosome 17 per cell [24].

\section{Quality Control and Gene Expression Analysis}

After quality control using a bioanalyzer (Agilent 2100), RNAs were labeled according to the Affymetrix protocol using the Two Cycle labeling kit (Affymetrix, Santa Clara, Calif., USA). After hybridization on Affymetrix HG-U133 Plus 2.0 chips (this dataset has been made publicly available at the Gene Expression Omnibus GEO database with submission number GSE29431), microarray data were normalized using different normalization meth- 
Table 1. Histological subtypes, basic demographic characteristics, IHC markers (ki67, p53, ER, PgR and HER2), HER2 DNA amplification and polysomy 17 of 54 breast cancer patients

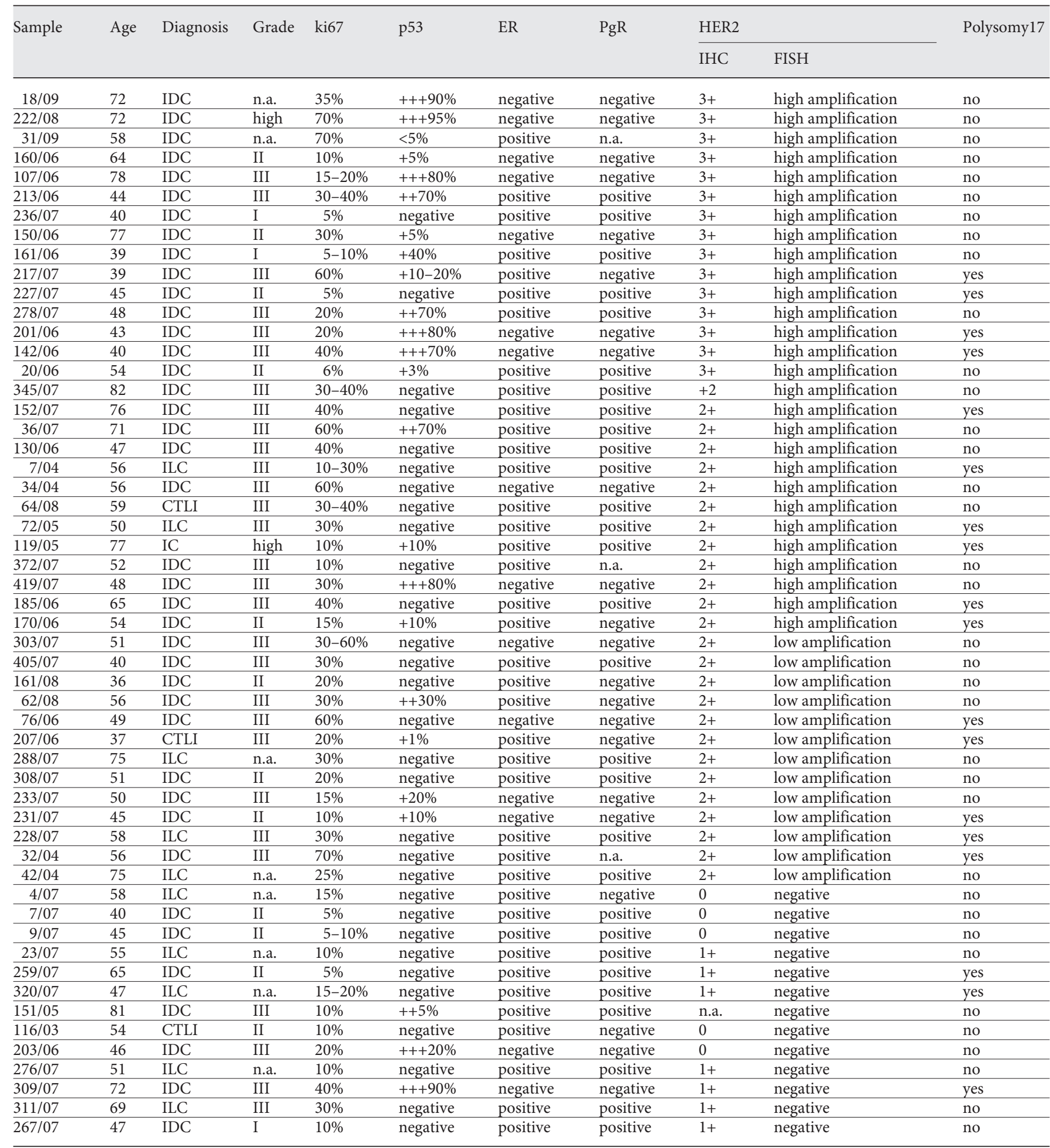

IC = Invasive carcinoma; IDC = invasive ductal carcinoma; IL = invasive lobular carcinoma; $\mathrm{n} . \mathrm{a} .=$ not available; NPI = Nottingham Prognostic Index; $\mathrm{TB}=$ tubular carcinoma. 
ods for Affymetrix arrays: RMA [25], GCRMA [26], MAS5 [27] and PLIER [28] which were implemented in the R software packages affy, gcrma and plier. The quality of the outcome was assessed by different plots produced by the R software package ArrayQualityMetrics [29]. Based on this outcome, we chose the RMA normalization method, as it best fits our data, and excluded 7 arrays from the process (2 IHC3+/FISH-positive, 2 IHC2+/ FISH-positive, 1 IHC2+/FISH-negative and 2 IHC01+/FISH-negative) (as shown in previous studies [30]) since these arrays showed significant biases in the averaged expression values which could not be corrected by the normalization methods.

Samples were grouped into categories according to their HER2 status, and the differential expression of genes between the different HER2-status groups and control samples was then evaluated using the Significance Analysis of Microarrays (SAM) algorithm [31]. Genes with corrected $\mathrm{p}$ values $<0.05$ were considered significantly differentially expressed between the compared groups.

Functional Analysis of Gene Expression Results

To interpret and check the biological coherence of the gene signatures obtained from the microarray analyses, we used the software Ingenuity Pathways Analysis v.5.0 (Ingenuity Systems Inc.). This annotation and work-mapping tool provides information about diseases, molecular function and biological process categories as well as biological pathways related to a list of genes.

\section{Quantitative Reverse Transcription-PCR}

To validate microarray experiment data, we determined the level of expression of mRNAs by real-time quantitative reverse transcription-PCR. In addition to HER2, we selected another 6 genes (CALD1, EPLIN, GRB7, LIMK, RHOF and TPM4) which significantly differentiated HER2-positive and HER2-negative breast tumor samples, and these were included in a motility signature. These genes were analyzed in 46 samples. Some of these tumors were cases not included in the microarray experiments. Expression was quantified following the analysis of 2 different dilutions of cDNAs (1 and 1/10) in triplicate. For each experimental sample, the amount of the each gene and endogenous reference (GAPDH) [32] was determined from the standard curves. These standard curves were composed of 6 points obtained from 7 -fold serial dilutions $(1,1 / 10,1 / 50,1 / 100,1 / 200$, $1 / 1,000$ and 1/2,000) of cDNA from mRNA breast tumor cell lines (JIMT1, MDA-MB-231 and SKBR3). We considered only the experiments in which the linear relationship between $\mathrm{Ct}$ (threshold cycle) and the log of the amount of standard curve for HER2 and GAPDH were higher than 0.99 (correlation coefficient). The expression values of each gene were then divided by the amount of GAPDH to obtain a normalized value. The gene GAPDH was used as an internal control for RNA quality reverse transcription, and to correct the variations in the degree of RNA degradation.

\section{Statistical Analysis}

Statistical significance of differences in transcript levels was assessed using the Student $t$ test. Data analyses were carried out with the SPSS statistical software, version 15.0 (SPSS Inc., Chicago, Ill., USA).

\section{Results}

\section{Gene Expression Profiles of Breast Cancer according} to HER2 Status

To establish the expression profiles of breast cancer based on HER2 status determined by IHC and FISH techniques, we analyzed 47 breast tumor samples representing 4 groups of HER2: 13 IHC3+ (FISH-positive), 11 IHC2+ (FISH-positive), 12 IHC2+ (FISH-negative) and 11 IHC01+ (FISH-negative).

A supervised method (SAM) was used to search for a gene signature showing significant differences between its expression profiles for IHC3+ and IHC2+ (FISH-positive) breast tumors. However, this method could not find any genes showing significantly different behavior between these 2 subgroups. The absence of significant molecular differences between IHC3+ and IHC2+ (FISHpositive) tumors supports the benefit of trastuzumab also in IHC2+ (FISH-positive) breast tumor patients.

Furthermore, the comparison between IHC2+ (FISHnegative) and IHC0/1+ tumors did not reveal many statistically significant differences in their expression profiles, although the HER2 protein expression pattern of the tumors of these groups was different. Only the vacuolar protein sorting 18 homolog gen, VPS18, was differently regulated.

The same method was used to find significant (adjusted $\mathrm{p}<0.05)$ differentially expressed genes between the breast tumor subgroups based on HER2 FISH results. We found that 629 genes were differentially expressed ( $\mathrm{p}<$ 0.05 ) between tumors with and without HER2 gene amplification; 143 of these presented significantly higher expression levels (overexpression) in HER2-positive tumors.

A hierarchical clustering analysis was then performed on both the genes and the samples based on the expression values of these 629 genes in the 47 tumoral samples (fig. 1). Samples were clustered into 2 main groups (branches) and genes were clustered into 7 groups. One of the groups of samples contained HER2-positive tumors and only one HER2-negative tumor (IHC2+/FISHnegative); this subgroup was characterized by a low expression level of 3 gene clusters (clusters A, B and C). The other branch of samples contained the remaining HER2positive samples and the HER2-negative samples; this subgroup also contained 3 branches, showing some degree of heterogeneity among tumors. Differences in the expression of the genes between the HER2-positive and HER2-negative tumor samples cannot be explained by a different content of tumor cells within the samples, since 


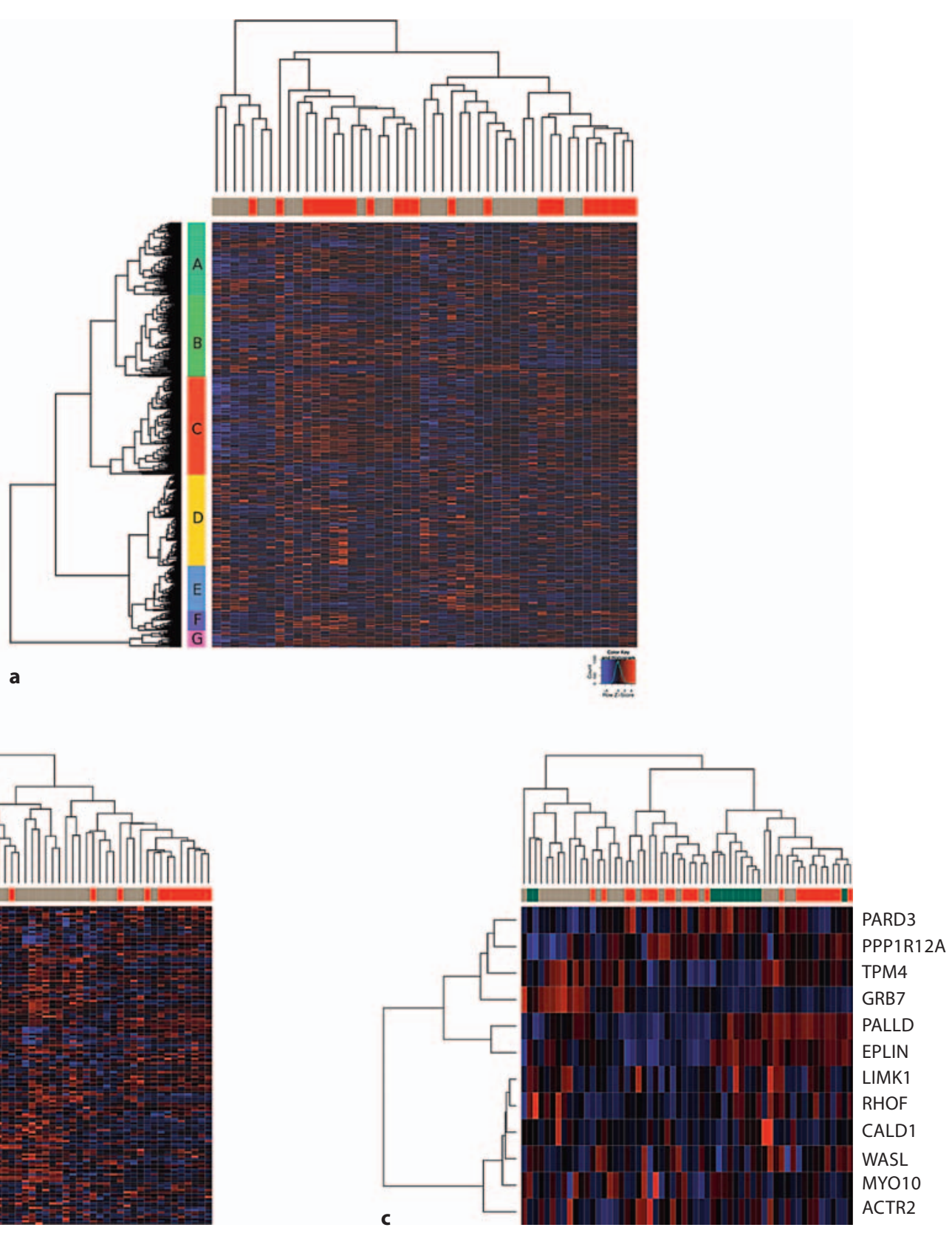

Fig. 1. a Breast tumor samples were clustered according to the expression of 629 genes differentially expressed $(p<0.05)$ between tumors with and without HER2 gene amplification. Seven different clusters are shown (A-G), illustrating significant differences among tumors. b Clustering based on the expression of 143 genes with higher expression in HER2-positive tumors. c Breast tumor

motility signature. Horizontal bar across top: grey = tumors with HER2 amplification, red = tumors without HER2 amplification and green $=$ normal breast tissue samples. Main part of figure: blue represents downregulation in the gene expression and red represents overexpression. 
Fig. 2. Localization of genes from the chromosome $17 \mathrm{q} 12-21$ region represented on genes expressed differently between HER2-positive and HER2-negative breast tumors.

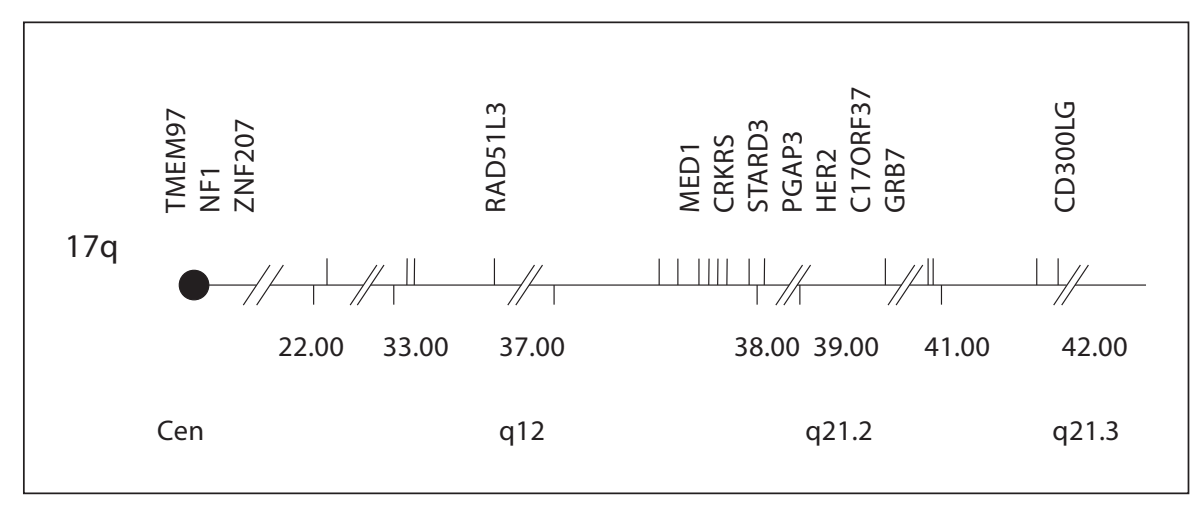

the estimation of tumor cells in the tumor samples showed no significant differences in the 2 groups (data not shown).

The IPA software tool outcome showed Cancer as the most significant disorder associated to the set of 629 genes (evidence supporting this association was found for 103 out of the 629 molecules). The main molecular and cellular function categories assigned to the gene set were Gene Expression and Cell Cycle, respectively. With respect to the networks, Cell-to-Cell Signaling and Interaction, Cellular Growth and Proliferation, Gene Expression, Tissue Morphology and Carbohydrate Metabolism were the most significantly associated to this set of genes.

In order to better understand the biological meaning of genes showing higher expression levels in HER2-positive tumors, data from these 143 genes were analyzed (fig. 1b). Inflammatory Disease, Genetic Disorder and Cancer were the main biological disorders (involving 33, 10 and 6 genes, respectively). In the molecular and cellular function category, most of these genes were associated with Gene Expression and Cellular Movement. In addition, the IPA analysis identified an important number of these genes involved in Cell Growth and Proliferation, Cell Cycle, Gene Expression, Cell Death, Cell-to-Cell Signaling and Interaction, Cellular Growth and Proliferation and the Cellular Movement, Cancer, and Immune Cell Trafficking networks. A detailed analysis of the overexpressed genes identified genes $(\mathrm{p}<0.05)$ encoding proteins associated with several canonical pathways, such as Regulation of Actin-based Motility by Rho, cdc42 Signaling, Integrin Signaling, Germ Cell-Sertoli Cell Junction and DNA Methylation and Transcriptional Repression Signaling. Interestingly, there was a high degree of overlapping between the genes associated with these functions, suggesting that they could play an important role in the HER2-positive tumor pathogenesis. Considering only the motility signatures, we obtained a signature of 12 genes that were clearly representative of HER2-positive cells and included most of the key cellular migration genes mentioned. This molecular signature related to migration included: ACTR2, CALD1, EPLIN, GRB7, LIMK, MYO10, PALLD, PARD3, PPP1R12A, ROHF, TPM4 and WASL (supplementary material). As shown in figure 1c, tumors with HER2 amplification presented a more similar expression pattern for this gene signature than tumors without HER2 amplification. Most of the samples representing normal breast tissue were grouped together. Clearly, the expression pattern of normal breast tissues was significantly different from tumors, indicating that the increased or decreased expression of at least some of these genes in breast cancer samples could be related with the tumoral process.

Finally, we analyzed the genes with lower expression levels in FISH-positive breast tumors using IPA. These genes were associated with the same diseases (Cancer and Genetic Disorder), as well as the same molecular and cellular functions (Gene Expression and Cell Cycle). The most significant networks were those related to Gene Expression, Cell Cycle, Cellular development (with 49 genes) and RNA Post-Transcriptional Modifications, Gene Expression and RNA Trafficking (with 37 genes). Furthermore, the Aminoacyl-tRNA Biosynthesis process was significantly represented $(\mathrm{p}<0.05)$ in downregulated genes, including the LARS, MARS2 and WARS2 synthetases.

\section{Detailed Analysis of Chromosome 17-Specific Genes}

In addition to HER2, another 6 genes located on region $\mathrm{q} 12$ of chromosome 17 were found to show significantly different behavior in HER2-positive versus HER2negative tumors (see fig. 2). HER2 and 5 of these genes showed higher expression levels in HER2-positive than in HER2-negative breast tumors. As expected, this set of 5 
also included the genes GRB7 and MED1 which were previously shown to be coamplified with HER2. The other genes overexpressed in HER2-positive breast tumors and located on 17q12 are STARD3, C17ORF37, PERLD1 and CRKRS. The coexpression of this set of genes could indicate coamplification, regulated by HER 2 and coregulated by the same factors. It may also lead to an association with an unknown phenotypic feature of the disease.

Furthermore, the gene RAD51L3, located upstream of CRKRS, showed lower expression levels in HER2-positive tumors. In addition, 3 other genes (TMEM97, ZNF207 and NF1) which are close to HER2 locus and located in 17q11.2, were downregulated in HER2-positive tumors, delimiting the downstream overexpressed region.

\section{Quantitative RT-PCR Validation of Genes Related to HER2}

We analyzed the mRNA expression levels of 7 genes (HER2, CALD1, EPLIN, GRB7, LIMK, RHOF and TPM4) by qRT-PCR in 46 breast tumors divided into 2 subgroups based on HER2 FISH results: 21 HER2 FISH-negative, and 25 HER2 FISH-positive.

The expression of HER 2 amplicon was studied analyzing the HER2 and GRB7 mRNA. The functions of the other genes are well known and are implicated in regulating cytoskeleton actin filaments. The EPLIN gene (epithelial protein lost in neoplasm, also known as LIMA-1) functions to link the cadherin-catenin complex to F-actin and simultaneously stabilizes this population of actin fibers, resulting in the establishment of the adhesion. LIMK regulates organization of actin cytoskeleton through inactivating phosphorylation of the actin depolymerizing family protein cofilin. RHOF causes the formation of thin, actin-rich surface projections. TPM4 provides stability to the filaments and regulate access of other actin-binding proteins.

The measurement of gene expression levels determined by microarray positively correlated with the qRTPCR analysis. Both microarray and qRT-PCR results confirmed similar trend of gene expression profile of selected genes in rectal cancer patients. As occurred in the microarray expression analysis, we found significant differences between the expression of CALD1 ( $\mathrm{p}=0.028)$, EPLIN $(\mathrm{p}=0.005), \operatorname{GRB} 7(\mathrm{p}=0.032), \operatorname{HER} 2(\mathrm{p}=0.006)$ and LIMK $(\mathrm{p}=0.018)$ genes in 2 subgroups (FISH-positive vs. FISH-negative). RHOF $(\mathrm{p}=0.063)$ and TPM4 $(\mathrm{p}=0.063)$ showed higher expression in FISH-positive tumors, although this did not reach statistical significance.

\section{Discussion}

Microarray experiments for breast cancer tumors have been carried out widely, but expression profiling of breast tumor classification based on HER2 status has only been performed in a few studies [15-17]. Expression profiling in breast tumors could facilitate progress on HER2 typing, allowing a better classification of tumors, the identification of undiscovered oncogenic pathways or the prediction of outcome or response to therapy.

We used gene expression data from microarrays to carry out a detailed study on the features of tumors according to HER2 IHC and FISH results. For this purpose, we compared the gene expression profile of HER2-positive and HER2-negative breast tumors. We did not find any statistically significant difference intragroups (among the HER2 IHC-positive samples and among the HER2 IHC-negative samples, respectively), supporting the reliability of HER2 FISH classification.

However, the applied statistical methods revealed a set of 629 genes showing significantly different behavior between the 2 subgroups based on FISH classification. Their functional analysis of using Ingenuity Pathway Analysis confirmed Cancer as the main disorder associated to these genes. The most significant functions were Cell-toCell Signaling and Interaction and Cellular Growth and Proliferation. These findings are consistent with the pathogenesis of cancer, characterized by the loss of control of cellular growth leading to the uncontrolled proliferation and activation of multiple cell-to-cell signaling pathways.

On the basis of genes that showed overexpression rates in HER2 FISH-positive tumors versus HER2 FISH-negative tumors, we identified an interesting core of genes located at 17q12-q21. This core includes HER2, GRB7, MED1, STARD3, C17ORF37, PERLD1 and CRKRS. They defined a small core region of coexpressed genes which are also probably coamplified, although the regulatory mechanisms leading to this overexpression remain unclear. Furthermore, the expression profiles of these genes could play an important role in the outcome of patients [14] and various gene expression signatures containing several $17 q$ genes have been reported [7, 15-18, 33, 34]. It is evident that the HER2-amplicon is variable and that it includes other upregulated genes located on $17 \mathrm{q}$, such as TOP2A, CDC6, RPL19 which are not included in our chromosome-17-specific signature. This might be due to the differences in the categorization of breast tumor samples of the different studies and the variability of gains of region 17q12-21. In this study, the evaluation of HER2 
mRNA expression levels showed a statistically significant correlation with DNA amplification, confirming the trend observed in our previous report [35]. However, qRT-PCR is an extremely sensitive and specific technique and there is also substantial scientific documentation supporting the variability of HER2 mRNA analysis among IHC and FISH categories [36-38].

The IPA software tool confirmed the overrepresentation of cell-to-cell signaling and interaction genes in the set of genes discriminating the HER2 FISH-positive and HER2 FISH-negative tumors. Some of these genes, such as ACTR2, LIMK, PPP1R12A and WASL, were jointly involved in the regulation of actin based on motility by Rho, cdc42 signaling and integrin signaling. The ASAP1, CALD1, EPLIN, GRB7, PARD3 and RHOF genes were also involved in at least one of the previous pathways. The presence of SH2-containing adapter protein GRB7, described previously in chromosome-17-specific signature, supported that the GRB7 gene could not merely be a silent passenger of the HER2 amplicon. It can interact with phosphorylated HER2, mediate aspects of cell migration through binding with focal adhesion kinase [33] and has been proposed as one of the genes in an HER2 gene signature related to outcome [39]. Information on the EPLIN and LIMK in breast cancer in the literature of any type is limited. For this reason, one of the most important observations of this study is that EPLIN transcriptionally expressed low levels in breast cancer tissues. Deple- tion of EPLIN disrupted not only the apical actin assembly but also the adhesion belt $[40,41]$. We also report the LIMK overexpression in FISH-positive breast tumors which could lead to enhanced tumor angiogenesis and metastasis. However, the precise mechanism of EPLIN and LIMK action is yet to be fully established. In addition, we could also find genes involved in migration, such as MYO10, which acts downstream of cdc 42 and can promote filopodia in the absence of VASP proteins [42], PALLD, a component of actin-containing microfilaments that is involved in the control of cell shape, adhesion and contraction [43] and TPM4, a member of the cytoskeletal family of proteins, implicated in stabilizing cytoskeleton actin filaments [44]. These findings support the existence of distinct genetic pathways of tumor evolution common to HER2-positive tumors, which underlie the pathogenesis of the different breast tumor subgroups and may explain their distinct biological role.

\section{Acknowledgements}

The authors are grateful to Calderón P, Galvez MD, García I at Tissues and Tumors Bank of the Universitary Hospital Virgen de las Nieves for collecting the samples. Parts of this study were supported by projects P08-TIC-4299 and CTS2200 of J.A., Sevilla, TIN2009-13489 of DGICT, Madrid, and GREIB-PYR-2010-02, GREIB-PYR-2012-05 of the University of Granada.

\section{References}

1 Slamon DJ, Clark GM, Wong SG, Levin WJ, Ullrich A, McGuire WL: Human breast cancer: correlation of relapse and survival with amplification of the HER-2/neu oncogene. Science 1987;235:177-182.

-2 Slamon DJ, Godolphin W, Jones LA, Holt JA, Wong SG, Keith DE, Levin WJ, Stuart SG, Udove J, Ullrich A: Studies of the HER-2/neu proto-oncogene in human breast and ovarian cancer. Science 1989;244:707-712.

3 Vogel CL, Cobleigh MA, Tripathy D, Gutheil JC, Harris LN, Fehrenbacher L, Slamon DJ, Murphy M, Novotny WF, Burchmore M, Shak S, Stewart SJ, et al: Efficacy and safety of trastuzumab as a single agent in first-line treatment of HER2-overexpressing metastatic breast cancer. J Clin Oncol 2002;20: 719-726.
4 Piccart-Gebhart MJ, Procter M, LeylandJones B, Goldhirsch A, Untch M, Smith I, Gianni L, Baselga J, Bell R, Jackisch C, Cameron $\mathrm{D}$, Dowsett $\mathrm{M}$, et al: Herceptin Adjuvant (HERA) Trial Study Team: trastuzumab after adjuvant chemotherapy in HER2-positive breast cancer. N Engl J Med 2005;353: 1659-1672.

5 Cuadros M, Villegas R: Systematic review of HER2 breast cancer testing. Appl Immunohistochem Mol Morphol 2009;17:1-7.

-6 Perou CM, Sorlie T, Eisen MB, van de Rijn M, Jeffrey SS, Rees CA, Pollack JR, Ross DT, Johnsen $\mathrm{H}$, Akslen LA, Fluge O, Pergamenschikov A, et al: Molecular portraits of human breast tumours. Nature 2000;406:747-752.

7 Sorlie T, Tibshirani R, Parker J, Hastie T, Marron JS, Nobel A, Deng S, Johnsen H, Pesich R, Geisler S, Demeter J, Perou CM, et al: Repeated observation of breast tumor subtypes in independent gene expression data set. Proc Natl Acad Sci USA 2003;100: 8418-8423.
8 Sorlie T, Perou CM, Tibshirani R, Aas T, Geisler S, Johnsen H, Hastie T, Eisen MB, van de Rijn M, Jeffrey SS, Thorsen T, Quist H, et al: Gene expression patterns of breast carcinomas distinguish tumor subclasses with clinical implications. Proc Natl Acad Sci USA 2001;98:10869-10874.

-9 Naderi A, Ahmed AA, Wang Y, Brenton JD, Caldas C: Optimal amounts of fluorescent dye improve expression microarray results in tumor specimens. Mol Biotechnol 2005; 30:151-154.

10 Karlsson E, Delle U, Danielsson A, Olsson B, Abel F, Karlsson P, Helou K: Gene expression variation to predict 10 -year survival in lymph-node-negative breast cancer. BMC Cancer 2008;8:254.

11 van 't Veer LJ, Dai H, van de Vijver MJ, He YD, Hart AA, Mao M, Peterse HL, van der Kooy K, Marton MJ, Witteveen AT, Schreiber GJ, Kerkhoven RM, et al: Gene expression profiling predicts clinical outcome of breast cancer. Nature 2002;415:530-536. 
12 Wang Y, Klijn JG, Zhang Y, Sieuwerts AM, Look MP, Yang F et al.: Gene-expression profiles to predict distant metastasis of lymphnode-negative primary breast cancer. Lancet 2005;365:671-679.

-13 Mook S, Knauer M, Bueno-de-Mesquita JM, Retel VP, Wesseling J, Linn SC, Van't Veer LJ, Rutgers EJ: Metastatic potential of T1 breast cancer can be predicted by the 70-gene MammaPrint signature. Ann Surg Oncol 2010;17:1406-1413.

- 14 Cuadros M, Llanos A: Validation and clinical application of MammaPrint ${ }^{\circledR}$ in patients with breast cancer. Med Clin (Barc) 2011; 136:627-632.

-15 Bertucci F, Finetti P, Birnbaum D, Viens P: Gene expression profiling of inflammatory breast cancer. Cancer 2010;116(11 suppl):2783-2793.

- 16 Bertucci F, Borie N, Ginestier C, Groulet A, Charafe-Jauffret E, Adélaïde J, Geneix J, Bachelart L, Finetti P, Koki A, Hermitte F, Hassoun J, et al: Identification and validation of an ERBB2 gene expression signature in breast cancers. Oncogene 2004;23:25642575.

-17 Wilson KS, Roberts H, Leek R, Harris AL, Geradts J: Differential gene expression patterns in HER2/neu-positive and -negative breast cancer cell lines and tissues. Am J Pathol 2002;161:1171-1185.

18 Sircoulomb F, Bekhouche I, Finetti P, Adélaide J, Ben Hamida A, Bonansea J, Raynaud S, Innocenti C, Charafe-Jauffret E, Tarpin C, Ben Ayed F, Viens P, et al: Genome profiling of ERBB2-amplified breast cancers. BMC Cancer 2010;10:539.

19 Holbro T, Civenni G, Hynes NE: The ErbB receptors and their role in cancer progression. Exp Cell Res 2003;284:99-110.

20 Harvey JM, Clark GM, Osborne CK, Allred DC: Estrogen receptor status by immunohistochemistry is superior to the ligand-binding assay for predicting response to adjuvant endocrine therapy in breast cancer. J Clin Oncol 1999;17:1474-1481.

21 Wolff AC, Hammond ME, Schwartz JN, Hagerty KL, Allred DC, Cote RJ, Dowsett M, Fitzgibbons PL, Hanna WM, Langer A, McShane LM, Paik S, et al: American Society of Clinical Oncology/College of American Pathologists guideline recommendations for human epidermal growth factor receptor 2 testing in breast cancer. J Clin Oncol 2007; 25:118-145.

-22 Wolff AC, Hammond ME, Schwartz JN, Hagerty KL, Allred DC, Cote RJ, Dowsett M, Fitzgibbons PL, Hanna WM, Langer A, McShane LM, Paik S, et al: American Society of Clinical Oncology/College of American Pathologists guideline recommendations for human epidermal growth factor receptor 2 testing in breast cancer. Arch Pathol Lab Med 2007;131:18-43.
3 Sauter G, Lee J, Bartlett JM, Slamon DJ, Press MF: Guidelines for human epidermal growth factor receptor 2 testing: biologic and methodologic considerations. J Clin Oncol 2009; 27:1323-1333.

4 Salido M, Tusquets I, Corominas JM, Suarez M, Espinet B, Corzo C, Bellet M, Fabregat X, Serrano S, Solé F: Polysomy of chromosome 17 in breast cancer tumors showing an overexpression of ERBB2: a study of 175 cases using fluorescence in situ hybridization and immunohistochemistry. Breast Cancer Res 2005;7:R267-R273.

25 Irizarry RA, Bolstad BM, Collin F, Cope LM, Hobbs B, Speed TP: Summaries of Affymetrix GeneChip probe level data. Nucleic Acids Res 2006;31:e15.

$26 \mathrm{Wu}$ Z, Irizarry RA: Stochastic models inspired by hybridization theory for short oligonucleotide arrays. J Comput Biol 2005; 12: 882-893.

27 Li C, Wong WH: Model-based analysis of oligonucleotide arrays: expression index computation and outlier detection. Proc Natl Acad Sci USA 2001;98:31-36.

28 Guide to Probe Logarithmic Intensity Error (PLIER) Estimation. http://www.affymetrix.com/support/technical/technotes/plier_technote.pdf.

29 Kauffmann A, Gentleman R, Huber W: ArrayQualityMetrics - a bioconductor package for quality assessment of microarray data. Bioinformatics 2009;25:415-416.

30 Reimers M: Making informed choices about microarray data analysis. PLoS Comput Biol 2010;6:e1000786.

- 31 Tusher VG, Tibshirani R, Chu G: Significance analysis of microarrays applied to the ionizing radiation response. Proc Natl Acad Sci USA 2001;98:5116-5121.

32 Vanden BI, Vanhentenrijk V, Drijkoningen M, Wlodarska I, Vandenberghe P, WolfPeeters C: Real-time reverse transcriptionPCR and fluorescence in-situ hybridization are complementary to understand the mechanisms involved in HER-2/neu overexpression in human breast carcinomas. Histopathology 2005;46:431-441.

33 Staaf J, Jönsson G, Ringnér M, Vallon-Christersson J, Grabau D, Arason A, Gunnarsson $\mathrm{H}$, Agnarsson BA, Malmström PO, Johannsson OT, Loman N, Barkardottir RB, et al: Research article High-resolution genomic and expression analyses of copy number alterations in HER2-amplified breast cancer. Breast Cancer Res 2010;12:R25.
34 Dressman MA, Baras A, Malinowski R, Alvis $\mathrm{LB}$, Kwon I, Walz TM, Polymeropoulos $\mathrm{MH}$ : Gene expression profiling detects gene amplification and differentiates tumor types in breast cancer. Cancer Res 2003;63:21942199.

35 Cuadros M, Talavera P, López FJ, GarcíaPeréz I, Blanco A, Concha A: Real-Time RTPCR analysis for evaluating the Her2/neu status in breast cancer. Pathobiology 2010; 77:38-45.

36 Gjerdrum LM, Sorensen BS, Kjeldsen E, Sorensen FB, Nexo E, Hamilton-Dutoit S: Realtime quantitative PCR of microdissected paraffin-embedded breast carcinoma: an alternative method for HER-2/neu analysis. J Mol Diagn 2004;6:42-51.

-37 Capizzi E, Gruppioni E, Grigioni AD, Gabusi E, Grassigli A, Grigioni WF, Fiorentino M: Real time RT-PCR approach for the evaluation of ERBB2 overexpression in breast cancer archival samples: a comparative study with FISH, SISH, and immunohistochemistry. Diagn Mol Pathol 2008;17:220-226.

- 38 Barberis M, Pellegrini C, Cannone M, Arizzi C, Coggi G, Bosari S: Quantitative PCR and HER2 testing in breast cancer: a technical and cost-effectiveness analysis. Am J Clin Pathol 2008;129:563-570.

39 Staaf J, Ringner M, Vallon-Christersson J, Jonsson G, Bendahl PO, Holm K, Arason A, Gunnarsson H, Hegardt C, Agnarsson BA, Luts L, Grabau D, et al: Identification of subtypes in HER2-positive breast cancer reveals a gene signature prognostic of outcome. J Clin Oncol 2010;28:1813-1820.

40 Abe K, Takeichi M: EPLIN mediates linkage of the cadherin catenin complex to F-actin and stabilizes the circumferential actin belt. Proc Natl Acad Sci USA 2008;105:13-19.

41 Jiang WG, Martin TA, Lewis-Russell JM, Douglas-Jones A, Ye L, Mansel RE: Eplinalpha expression in human breast cancer, the impact on cellular migration and clinical outcome. Mol Cancer 2008;16:7:71.

42 Bohil AB, Robertson BW, Cheney RE: Myo$\sin -\mathrm{X}$ is a molecular motor that functions in filopodia formation. Proc Natl Acad Sci USA 2006;103:12411-12416.

43 Boukhelifa M, Moza M, Johansson T, Rachlin A, Parast M, Huttelmaier S, Roy P, Jockusch BM, Carpen O, Karlsson R, Otey CA: The proline-rich protein palladin is a binding partner for profilin. FEBS J 2006;273: 26-33.

44 Vlahovich N, Schevzov G, Nair-Shaliker V, Ilkovski B, Artap ST, Joya JE, Kee AJ, North KN, Gunning PW, Hardeman EC: Tropomyosin 4 defines novel filaments in skeletal muscle associated with muscle remodelling/ regeneration in normal and diseased muscle. Cell Motil Cytoskeleton 2008;65:73-85. 